\title{
A ORIENTAÇÃO EDUCACIONAL NO CEFET-RN FRENTE ÀS POLÍTICAS DE EDUCAÇÃO PROFISSIONAL E DE ENSINO MÉDIO NO BRASIL (1995-2005)
}

\author{
U. Á. PEREIRA, M. G. S. SOUSA e O. M. MEDEIROS NETA* \\ Instituto Federal do Rio Grande do Norte \\ olivia.neta@ifrn.edu.br*
}

Artigo submetido em abril/2014 e aceito em novembro/2014

DOI: $10.15628 /$ holos.2014.2099

\section{RESUMO}

Este artigo visa analisar as políticas de educação profissional no Brasil a partir dos anos 1990 e as suas repercussões no trabalho do Orientador Educacional do CEFET-RN, em 1995, 1999 e 2005, respectivamente, no governo do Presidente Fernando Henrique Cardoso e do Presidente Luiz Inácio Lula da Silva. Em consequência dessas políticas, a Instituição teve que redimensionar os seus projetos pedagógicos de acordo com as diretrizes que as orientam. Nesse contexto, o trabalho desenvolvido pelo orientador educacional reconfigurouse. Isso nos motivou a investigar como foi desenvolvido esse trabalho na Instituição e quais as suas implicações para a formação dos estudantes da 1a série dos cursos técnicos de nível médio. Para isso, realizamos uma revisão da literatura e procedemos à análise de documentos. $O$ estudo está referendado na pedagogia histórico-crítica. A pesquisa apontou que a reforma da educação profissional brasileira a partir dos anos 1990 contribuiu para a (des)configuração desse trabalho e que o seu replanejamento, no ano de 2005, trouxe contribuições relevantes ao trabalho do Orientador Educacional e aos estudantes.

PALAVRAS-CHAVE: Reforma da Educação Brasileira. Orientação Educacional. Formação.

\section{HE EDUCATIONAL ORIENTATION AT CEFET-RN IN RELATION TO THE PROFESSIONAL AND MID-LEVEL EDUCATION POLICIES IN BRAZIL (1995-2005)}

\begin{abstract}
This article aims to analyse professional education policies in Brazil from 1990 onwards and their repercussion in the work of Educational Counsellors at CEFET-RN, in 1995, 1999 and 2005, during the presidencies of Fernando Henriques Cardoso and Luís Inácio Lula da Silva. As a consequence of these policies, the Institution had to re-measure its pedagogical projects according to the guidelines in use at those periods. In this context, the work developed by Educational Counsellors has acquired new configurations. This has motivated us to investigate how this work has been developed in the institution and what its implications are for the training
\end{abstract}

of students of the 1st series of mid-level technical courses. In order to do that, we carried out a review of literature and simultaneously proceeded with an analysis of documents. This study has for reference the historicalcritical pedagogy. The research has shown that the reform of Brazilian professional education from 1990 onwards has contributed to a regression as far as that work is concerned and that a new planning, which occurred in 2005, brought about relevant contributions to the work of Educational Counsellors as well as to the students.

KEYWORDS: Brazilian Education Reform. Educational Orientation. Training. 


\section{INTRODUÇÃO}

A reforma administrativa do Estado brasileiro, em 1995, e a operacionalização do "Plano Diretor da Reforma do Estado" no governo de Fernando Henrique Cardoso (1994-2002) deram início a várias reformas que atingiram inclusive a área da educação.

Nesse contexto, esse governo implementou políticas educacionais de cunho gerencialista nas instituições de ensino coerentes com a estratégia econômica neoliberal que possui - dentre as suas características - a intensificação da globalização. Essas políticas eram orientadas pelos organismos financeiros internacionais, responsáveis pelo financiamento de políticas voltadas à adequação dos países periféricos à nova lógica do capital. Assim sendo, o Brasil adotou, de forma consistente, a lógica da racionalidade econômica na política educacional.

Em consequência disso, o então Centro Federal de Educação Tecnológica do Rio Grande do Norte, denominado oficialmente, desde dezembro de 2008, de Instituto Federal de Educação, Ciência e Tecnologia do Rio Grande do Norte - localizado na região nordeste do Brasil -, teve que se reestruturar para atender às exigências da ordem legal vigente na esfera educacional do país. Isso fez com que essa Instituição, de certa forma, perdesse a sua autonomia escolar.

Nesse sentido, a Instituição, comprometida com a educação socialmente referenciada, assumiu novas configurações, dentre elas, a contratação de consultores que elaboraram dois projetos pedagógicos para a Instituição: um destinado à educação profissional, em 1999, e outro, ao ensino médio, no ano 2000, atendendo, assim, as determinações do Decreto n. 2.208/97, que desintegrou os cursos ofertados na Instituição.

Na concepção de Cunha (2000, p. 256),

[...] com o Decreto 2.208/97, o ensino técnico foi definido como independente do ensino médio. Isso significava que um aluno poderia cursar o ensino técnico ao mesmo tempo em que o ensino médio, ou, então, depois deste. Os cursos chamados integrados, que ofereciam num mesmo currículo a educação geral de nível médio e a educação técnico-profissional, foram literalmente proibidos.

A implementação dessas políticas educacionais ocasionou ao CEFET-RN a extinção da sua atuação em cursos que buscavam articular, na esfera da educação profissional, a formação geral à formação profissional (CEFET-RN, 1995). Nessa nova realidade, passaram a ser oferecidos o ensino médio, a formação de professores para a educação básica e cursos de educação profissional nos níveis básico, técnico em currículo independente do ensino médio e tecnológico.

Além disso, a Instituição criou seis gerências educacionais, sendo uma delas destinada aos professores do ensino médio, e extinguiu a proposta curricular implementada pelo CEFET-RN, em 1995, que tinha como foco principal a formação integral do técnico-cidadão.

Nesse contexto, o trabalho de Orientação Educacional que era desenvolvido, semanalmente, em sala de aula, desde o ano de 1995, junto aos estudantes de 1 a série dos cursos técnicos de nível médio organizados em áreas de conhecimentos, foi extinto em 1999.

Posteriormente, com a eleição para presidente de Luiz Inácio Lula da Silva em 2002, e, diante do compromisso assumido por ele com sindicatos e educadores comprometidos com a 
educação de qualidade para todos os brasileiros, foi revogado o Decreto n. 2.208/97. Em seguida a essa revogação, foi aprovado o Decreto n. 5.154/2004, em 23 de julho de 2004, que possibilitou a integração curricular entre a educação profissional técnica de nível médio e o ensino médio.

Frente a esses contextos, optamos por analisar o trabalho de Orientação Educacional desenvolvido pelo CEFET-RN, no período do governo de Fernando Henrique Cardoso e de Luiz Inácio Lula da Silva.

Como recorte temporal temos os anos de 1995, 1999 e 2005, em decorrência de o CEFETRN ter redimensionado o seu trabalho didático-pedagógico com base na legislação em vigor e nos seus projetos pedagógicos.

Diante disso, questionamos: como foi desenvolvido o trabalho de Orientação Educacional, envolvendo estudantes de 1a série de cursos técnicos de nível médio do CEFET-RN, na faixa etária entre 13 e 15 anos, sendo 50\% destes, oriundos de escolas públicas do Estado do Rio Grande do Norte e quais as implicações desse trabalho para a formação desses estudantes?

Para efetivação do estudo, realizamos uma revisão da literatura e procedemos à análise de documentos oficiais elaborados na Instituição, tal como: uma proposta curricular implementada no ano de 1995 e projetos pedagógicos implementados em 1999 e 2005, além das leis em vigor nesses anos, as quais fixam as diretrizes e bases da educação nacional.

Este estudo está referendado na pedagogia histórico-crítica, a partir das ideias de Gramsci, que concebe o homem como um ser capaz de pensar e adquirir os elementos que o instrumentalizem para uma compreensão mais elaborada da sociedade, tornando-se capaz de assumir, no futuro, a gestão social.

A pedagogia histórico-crítica tem, dentre seus pressupostos de aprendizagem, a concepção dialética da história para compreender a educação escolar tal como se manifesta no presente. Essa manifestação é entendida como resultado de um longo processo de transformação histórica. Nessa perspectiva, a aprendizagem constitui-se em um ato de conhecimento a partir da situação real vivida pelo aluno, num processo de reflexão, compreensão e crítica.

Para Saviani (1991, p. 75), “a pedagogia histórico-crítica procura reter o caráter crítico de articulação com os condicionantes sociais que a visão reprodutivista possui, vinculado, porém, à dimensão histórica que o reprodutivismo perde de vista".

Com base na pedagogia histórico-crítica, os estudantes apreendem o processo de produção do saber produzido historicamente e as tendências de sua transformação. São considerados seres concretos, que têm possibilidades de discutir problemas a partir do contexto histórico onde estão inseridos. Essa pedagogia destaca também a relevância dos conteúdos vivenciados pelo estudante e não meramente os conteúdos acadêmicos.

\section{A PRÁTICA DE ORIENTAÇÃO EDUCACIONAL NO CEFET-RN: CONTEXTO POLÍTICO E IMPLEMENTAÇÃO}

O CEFET-RN foi criado em 1998, como Instituição responsável pela oferta de Educação Profissional, nos níveis básico, técnico e tecnológico. Teve sua origem em 1909, como Escola de Aprendizes de Artífices, com o objetivo de oferecer uma instrução primária e profissional aos filhos de trabalhadores(as) da classe economicamente desfavorecida. Passou, no século XX, por enormes 
mudanças nos aspectos educacionais, à medida que o Brasil sofria suas transformações no campo da economia, impulsionadas pelo processo de industrialização.

A aprovação do conjunto de Leis Orgânicas da Educação ao final dos anos 1940, assim como a promulgação das Leis n. 4.024/61 e n. 5.692/71 - esta última denominada de Lei da Reforma de Ensino de 10 e 20 Graus, - redimensionaram a prática educativa dessa Instituição. Com isso, vieram a equivalência do ensino profissional ao ensino médio, e, posteriormente, a integração do ensino médio à educação profissional com a publicação do Decreto n. 5.154/04, que revogou o Decreto n. 2.208/97, desvinculando o ensino médio da educação profissional.

Diante desses contextos, ressaltamos que a Orientação Educacional surge na então Escola Industrial Federal do Rio Grande do Norte, em 1965, antes da promulgação da Lei 5.540/68 da Reforma de Ensino Superior, que criou as habilitações de administração escolar, de supervisão escolar e orientação educacional no curso de pedagogia.

Nesse ano, o trabalho de Orientação Educacional era desenvolvido na referida Escola por um grupo de orientadores educacionais e assistentes sociais, sob a forma de atendimentos individuais e aplicação de testes vocacionais, numa perspectiva cognitivista.

Nos anos de 1970, com a publicação da Lei n. 5.692/71, a Orientação Educacional é inserida no currículo da Escola Técnica Federal do Rio Grande do Norte, anteriormente, denominada Escola Industrial Federal do Rio Grande do Norte. Essa inserção se deu no formato de atividade, conforme estabelecia o artigo 1으, da Lei n. 5.692/71.

Em relação aos anos de 1990, com a ascensão do neoliberalismo no Brasil, consolidado pela reestruturação produtiva e, consequentemente, pelas novas exigências de formação de um trabalhador polivalente, a Escola Técnica Federal do Rio Grande do Norte elaborou, em 1994, uma proposta curricular pautada nos princípios do materialismo histórico-dialético e da concepção de educação baseada nas ideias de Gramsci, em contraposição ao discurso neoliberal. Essa proposta curricular passa a ser implementada a partir de 1995, ano em que se inicia a extinção gradativa dos cursos técnicos organizados, predominantemente, com base na tendência tecnicista de educação.

Assim, a Instituição opta por um currículo integrado entre o ensino médio, à época 20 grau, e a formação profissional técnica. No currículo, insere o conceito de área de conhecimento, o que viabiliza a integração de diversos cursos anteriormente fragmentados. Dessa forma, foram criadas áreas de conhecimentos (Construção Civil, Eletromecânica, Informática, Serviços, Tecnologia Ambiental). Cada área tinha suas competências específicas de acordo com suas respectivas habilitações.

As bases do currículo envolviam uma concepção de homem considerado como ser historicamente situado, com capacidade de interferir na sua realidade para aceitá-la, rejeitá-la ou transformá-la; ser capaz de pensar, de adquirir os elementos que o instrumentalizassem para uma compreensão mais elaborada da realidade, tornando-se capaz de assumir, no futuro, a gestão social; ser historicamente determinado, que estabelece relações de produção numa sociedade de características definidas, constrói a sua consciência a partir da produção dos bens materiais de sua existência, das características da adolescência, do adulto jovem e das aprendizagens nessas fases.

Nessa proposta curricular, a Orientação Educacional passava a fazer parte da grade curricular dessas Áreas, sendo oferecida na 1a série, com uma hora/aula anual, desenvolvida em forma de atividade em sala de aula e, não como disciplina. Tinha como objetivo compreender, de 
forma crítica, o processo educativo que se realizava na Escola, como uma das condições favoráveis à assimilação ativa de conhecimentos, à aquisição de hábitos e habilidades, bem como ao desenvolvimento de atitudes indispensáveis à formação do técnico-cidadão.

Esse trabalho possibilitava aos estudantes conhecerem o funcionamento da escola nos seus aspectos administrativos e pedagógicos, discutirem a importância da organização dos estudos (estudar para quê?; como?), compreenderem o processo de organização do trabalho na "sociedade do conhecimento", discutirem a relevância de ser cidadão e a atuação do representante de classe no espaço escolar, além de estudarem temas como adolescência e sexualidade. Para isso, a proposta desse trabalho destacava a relevância do diálogo entre professor-estudante e vice-versa. Além disso, cabia ao Orientador Educacional trabalhar junto ao estudante as competências gerais da sua área de conhecimento profissional, objeto de sua escolha durante o processo seletivo.

Nesse sentido, o trabalho de Orientação Educacional visava à formação do técnico-cidadão, oportunizando ao estudante analisar a realidade e agir sobre ela, buscando a sua transformação social, uma vez que "[...] o novo currículo da ETFRN enfatiza o domínio do saber nos campos da ciência, da tecnologia e cultura, sem que isso signifique o armazenamento de informações estáticas e acríticas" (PROPOSTA CURRICULAR DO CEFET-RN, 1995, p. 79).

Acrescentamos a isso o fato de que o currículo da ETFRN também contemplava as reuniões de pais e a organização dos conselhos de classe realizados ao final de cada bimestre, com a finalidade de articular os diversos segmentos da escola, tais como: professores, estudantes, equipe gestora, pedagogos e representantes de pais, em torno da melhoria dos processos educacionais desenvolvidos. Assim sendo, o referido Conselho tinha como objetivos:

I - Avaliar o processo ensino-aprendizagem e encontrar, conjuntamente com gestores, equipe pedagógica, professores, alunos e pais alternativas de solução para os problemas detectados após cada bimestre letivo; II- Propor medidas de caráter didático-pedagógico, visando à melhoria do processo ensinoaprendizagem; III- Opinar junto à direção de ensino sobre assuntos que estejam envolvidos com o processo ensino-aprendizagem (ESCOLA TÉCNICA FEDERAL DO RIO GRANDE DO NORTE, 1997, p. 1).

Nessa perspectiva, o Conselho de Classe configurava-se como um espaço coletivo de articulação e mobilização da comunidade escolar sobre os temas de ensino e aprendizagem. A participação dos representantes de pais escolhidos por seus pares fortalecia a existência do Conselho e o trabalho desenvolvido pelo Orientador Educacional na coordenação desse processo.

Em contraposição aos princípios dessa proposta curricular, o governo federal publicou o Decreto n. 2.208/97 e a Portaria MEC n. 646/97, o que exigiu do CEFET-RN a reestruturação do seu currículo. Esses documentos regulamentaram a mais inadequada Reforma da Educação Profissional, de cunho utilitarista e inibidora da verdadeira democratização do conhecimento que formalizou a implementação de cursos técnicos aligeirados na Instituição em detrimento dos cursos que contemplavam uma estrutura curricular de formação geral e de formação profissionalizante com duração de quatro anos.

De acordo com Pereira (2010, p. 86), 
[...] o governo FHC reduziu, também, a oferta de ensino médio dos Cefets e das Escolas Técnicas Federais ao nível de $50 \%$ da oferta de 1997, conforme a Portaria n 646/1997, Art. 3o e oficializou a criação de cursos modulares, na forma de organização curricular sequencial ou concomitante segundo o Artigo 5o, do Decreto $n$ o 2.208/97. Essas medidas limitaram a autonomia dessas Instituições, impondo-Ihes um novo modelo pedagógico, comprometendo a sua qualidade em educação profissional, subordinando-as ao mercado de trabalho.

Os argumentos utilizados por especialistas do Ministério da Educação na implementação da Reforma da Educação Profissional para a Rede Federal de Educação Tecnológica, pautavam-se na justificativa de que o custo/aluno era demasiado caro para os cofres públicos, pois a maioria dos estudantes buscava ingressar nas Universidades, e não no mercado de trabalho. Esse discurso voltava-se para atender a lógica imediata de mercado, quebrando a concepção de uma educação para a formação da cidadania em uma perspectiva emancipatória.

Ao analisar criticamente a implementação dessa Reforma, observamos a sua interligação com as políticas nacionais de cunho neoliberal elaboradas em consonância com as orientações do Banco Mundial. Essas políticas foram impregnadas pelo discurso da redução da pobreza, de forma sustentada nos países em desenvolvimento. (KUENZER, 2001).

Ainda tratando-se de políticas neoliberais, citamos Paulo Freire ao ressaltar, em seu livro "A sombra desta mangueira", que:

A perspectiva neoliberal reforça a pseudo-neutralidade da prática educativa, reduzindo-a a transferência de conteúdos aos educandos, a quem não se exige que os apreendam para que os aprendam. Essa "neutralidade" fundamenta a redução da formação do torneiro em simples treino de técnicas e procedimentos no domínio do torno. Toda prática educativa que vá além disso, que evite a dicotomia leitura do mundo/leitura da palavra, leitura do texto/leitura do contexto, perde o aval da pedagogia e se transforma em mera ideologia. Mais ainda: em palavra inadequada ao momento atual, sem classes sociais, sem conflitos, sem sonhos, sem utopias (FREIRE, 2001, p. 32).

Diante desta afirmação de Paulo Freire, destacamos que a implementação dessas políticas na Instituição interferiram no trabalho de Orientação que vinha sendo desenvolvido. Esse trabalho, em 1999, voltou-se para o desenvolvimento de atividades que priorizavam as relações interpessoais e o autoconhecimento em uma visão mais psicológica, utilizando-se de dinâmicas de grupo realizadas em uma sala de aula organizada para esse fim. Porém, não houve a extinção das reuniões dos conselhos de classe.

Apesar disso, a intervenção do Orientador Educacional não passou a ser autocentrada e desvinculada da busca pelo trabalho coletivo, pois política é texto e ação, palavras e fatos, tanto o que é intencionado como o que é realizado (BALL, 1994).

Por isso, dentro de um processo dialético de retomada da função social da Instituição, surge o movimento de resistência às ideias neoliberais contidas nos documentos legais. Esse sentimento adquire força inclusive em meio aos estudantes, sendo o espaço de Orientação Educacional utilizado também com essa finalidade, ou seja, de conscientização para resistência à reforma da 
educação profissional que, do ponto de vista de educadores e estudantes, veio na contramão da história da educação profissional brasileira.

Segundo Giroux (1999, p. 220),

[...] a prática educacional deve expandir as potencialidades humanas para permitir às pessoas intervirem na formação de suas próprias subjetividades e serem capazes de exercer o poder no interesse de transformar as condições ideológicas e materiais da dominação em práticas sociais que promovam empoderamento social e demonstrem possibilidades. (destaque nosso).

Diferentemente do que defende Giroux, a implementação de novos projetos pedagógicos no CEFET-RN formalizou a dissociação entre ensino médio e educação profissional, respectivamente, a partir dos anos 2000 e 2001 . Nesse quadro, foi excluída da estrutura curricular dos cursos a Orientação Educacional.

Em outra perspectiva, antes da publicação do Decreto n. 5.154/2004, a Instituição iniciou, em 2003, a elaboração de um projeto político-pedagógico que foi implementado em 2005. Esse projeto evidenciava a busca pela formação do aluno-trabalhador-cidadão, intelectualmente autônomo, participativo, solidário, crítico e que exija uma (re)inserção digna na sociedade e no mundo do trabalho.

Dentre os princípios norteadores desse novo projeto, encontra-se o trabalho como princípio educativo que permite uma compreensão do significado econômico, social, histórico, político e cultural das ciências e das artes. Assumir o trabalho nessa perspectiva implica referir-se a uma formação baseada no processo histórico e ontológico de produção da existência humana, da qual a produção do conhecimento científico é uma dimensão.

No ano de 2005, porém, a Instituição decidiu inserir a Orientação Educacional nas matrizes curriculares dos cursos. Essa decisão fez com que Orientação Educacional passasse a ser assumida como disciplina, com carga horária de $2 \mathrm{~h}$ /aulas semanais no 1 을 semestre, em turmas de 10 ano dos Cursos de Ensino Médio Integrado à Educação Profissional oferecidos pela Instituição: Controle Ambiental, Edificações, Eletrotécnica, Geologia, Informática, Mecânica e Turismo.

Para procurar responder às exigências desse novo contexto, a partir desse novo projeto, o objetivo da Orientação Educacional foi redefinido. Assim, passou-se a compreender o processo de aprendizagem que se realiza na Instituição como uma das condições favoráveis para a organização do pensamento na busca do aprender a aprender e para o desenvolvimento de habilidades e atitudes indispensáveis à formação cidadã.

Dessa forma, foram trabalhados conteúdos sobre o papel dos estudantes no processo educativo, o desenvolvimento do processo ensino-aprendizagem, a ética, a política e a cidadania, além de temas de interesse dos estudantes. Desenvolveram-se também atividades de pesquisa, cujos resultados foram apresentados e discutidos em sala de aula.

Assim sendo, o CEFET-RN assumia que a pesquisa como princípio educativo deveria estar presente em todas as ofertas, independentemente do nível educacional e da faixa etária dos alunos, pois, localiza-se, de forma precípua, no campo das atitudes e dos valores. Sua forma de abordagem deveria ser adequada a todos os níveis e modalidades de ensino, por meio de 
estratégias, métodos e objetivos próprios de cada oferta e do amadurecimento intelectual de cada grupo de estudantes.

Na esfera dos valores, a pesquisa aplicada e o desenvolvimento tecnológico devem estar voltados para a produção de bens e serviços que tenham como finalidade melhorar as condições de vida dos coletivos sociais e não apenas de produzir bens de consumo para fortalecer o mercado e, em consequência, privilegiar o valor de troca em detrimento do valor de uso, concentrando riqueza e aumentando o fosso entre os incluídos e os excluídos (MOURA, 2004).

Evidentemente, a pesquisa também pode e deve estar orientada a aspectos mais acadêmicos das ciências da natureza, sociais e/ou aplicadas, mas sempre tendo em consideração a que interesses correspondem e a quem podem beneficiar os possíveis resultados alcançados.

Diante do exposto, a unidade ensino/pesquisa colabora para edificar a autonomia dos indivíduos, o desenvolvimento das suas capacidades potencializadas pela investigação e pela responsabilidade social que o discente assume. Na perspectiva Freireana, o estudante deixa de ser um 'depósito' de conhecimentos produzidos e transmitidos por outros e passa a construir, desconstruir e reconstruir suas próprias conviç̧ões a respeito da ciência, da tecnologia, do mundo e da própria vida. Na concepção de Freire (1996, p. 32): "Pesquiso para conhecer o que ainda não conheço e comunicar ou anunciar a novidade".

Dessa maneira, coerente com os conhecimentos e atitudes trabalhados em Orientação Educacional, a avaliação do processo de aprendizagem tinha o caráter de acompanhamento. Isso se configurava numa ação dialógica entre educadores-educandos e vice-versa, analisado e registrado de forma processual e contínua, procurando seguir as orientações do projeto políticopedagógico e da função social do CEFET-RN:

[...] promover a educação científico-tecnológico-humanística visando à formação integral do profissional-cidadão crítico-reflexivo, competente técnica e eticamente e comprometido efetivamente com as transformações sociais, políticas e culturais e em condições de atuar no mundo do trabalho na perspectiva da edificação de uma sociedade justa e igualitária, através da formação inicial e continuada de trabalhadores; da educação profissional técnica de nível médio; da educação profissional tecnológica de graduação e pós-graduação; e da formação de professores, fundamentadas na construção, reconstrução e transmissão do conhecimento (PROJETO POLÍTICO- PEDAGÓGICO DO CEFET-RN: EM CONSTRUÇÃO, 2004, p. 86).

De acordo com essa função social, a avaliação em Orientação Educacional busca a (re)construção do conhecimento e o desenvolvimento de hábitos e atitudes coerentes com a formação integral do profissional cidadão.

\section{CONSIDERAÇÕES FINAIS}

Diante do exposto, esta pesquisa apontou que o trabalho de Orientação Educacional desenvolvido no CEFET-RN em 1995 e 2005 estava estruturado de forma que os estudantes da 1a série dos cursos técnicos de nível médio compreendessem melhor as relações de trabalho e a relevância de sua participação mais efetiva na sociedade. Assim, isso contribuía, de forma significativa, para a sua formação. 
Além disso, possibilitava ao Orientador Educacional as condições necessárias para que pudesse refletir de forma crítica sobre a sua prática inserida em um contexto de diversas contradições. Nessa perspectiva, o trabalho desenvolvido pelo orientador educacional buscava a superação das dicotomias teoria-prática, saber-fazer, entre conhecimento científico e os saberes dos estudantes oriundos dos seus contextos sociais.

Ainda esta pesquisa evidenciou que a proposta curricular implementada em 1995 e o projeto político-pedagógico de 2005 consideravam a educação como um direito social - princípio, de extrema relevância, ao planejamento, desenvolvimento e avaliação do trabalho de Orientação Educacional na Instituição.

Por outro lado, o trabalho de Orientação Educacional, nessa Instituição, desconfigurou-se com a implementação da reforma da educação brasileira a partir dos 1990. Provavelmente, isso teve implicações insatisfatórias no processo de formação dos estudantes como sujeitos históricos e sociais.

No entanto, o replanejamento desse trabalho, no ano de 2005, como uma ação planejada e organizada a partir de objetivos claros, comprometidos com a busca pela formação integral dos estudantes, envolvendo aspectos sociais, políticos e pedagógicos fundamentais à intervenção do indivíduo na sociedade capitalista, possibilitou ao Orientador Educacional o desenvolvimento do seu trabalho em prol da formação de sujeitos que pudessem intervir na sociedade em função de todos os cidadãos.

\section{REFERÊNCIAS}

1. BALL, S. J. Educational reform: a critical and post-structural approach. Buckingham: Open University Press, 1994.

2. BRASIL. Lei n. 5.692, de 11 de agosto de 1971. Fixa diretrizes e bases para o ensino de 1 을 은 graus. Brasília: MEC, 1971.

3. CENTRO fEDERAL DE EDUCAÇÃO TECNOLÓGICA DO RIO GRANDE DO NORTE. Projeto Pedagógico do CEFET-RN: um documento em construção. Natal: CEFET-RN, 2004.

4. ESCOLA TÉCNICA FEDERAL DO RIO GRANDE DO NORTE. Proposta Curricular. Revista n. 09, Ano XII. Natal-RN, Janeiro, 1995.

5. FREIRE, Paulo. À sombra desta mangueira. São Paulo: Olho d'Água, 2001.

6. FREIRE, Paulo. Pedagogia da Autonomia: saberes necessários à prática educativa. 9. ed. São Paulo: Paz e Terra, 1996.

7. GIROUX, Henry A. Cruzando as fronteiras do discurso educacional: novas políticas em educação. Tradução: Magda França Lopes. Porto Alegre: Artes Médicas, 1999.

8. KUENZER, Acácia Zeneida. Ensino Médio construindo uma proposta para os que vivem do trabalho. 2. ed. São Paulo: Cortez, 2001.

9. MOURA, Dante Henrique. In: Projeto Pedagógico do CEFET-RN: um documento em construção. Natal: CEFET-RN, 2004.

10. PEREIRA, Ulisséia Ávila Pereira. Políticas de Educação Profissional Técnica e de Ensino Médio no Brasil: a implementação no CEFET-RN (1998-2008).2010. 308 f. Tese (Doutorado em 
Educação)- Universidade Federal do Rio Grande do Norte, Natal, 2010.

11. SAVIANI, Dermeval. Pedagogia Histórico-crítica: primeiras aproximações. 2. ed. São Paulo: Cortez, 1991. 